\title{
GERMINAÇÃO DE SEMENTES DE Blepharocalyx salicifolius (H.B.K.) Berg. EM DIFERENTES SUBSTRATOS E CONDIÇÕES DE TEMPERATURAS, LUZ E UMIDADE ${ }^{1}$
}

\author{
SUELEN SANTOS REGO², ANTONIO CARLOS NOGUEIRA ${ }^{3}$, YOSHIKO SAITO KUNIYOSHI", \\ ÁLVARO FIGUEREDO DOS SANTOS ${ }^{5}$
}

\begin{abstract}
RESUMO - O objetivo deste trabalho foi verificar a influência de diferentes temperaturas $\left(20^{\circ} \mathrm{C}\right.$, $25^{\circ} \mathrm{C}, 30^{\circ} \mathrm{C}$ e $35^{\circ} \mathrm{C}$ ), substratos (rolo de papel, papel-toalha, areia e vermiculita), condições de luz (ausência e presença) e umidade (substratos pouco úmido, úmido, muito úmido e encharcado) sobre a germinação de sementes de Blepharocalyx salicifolius. Os melhores resultados são obtidos com os substratos papel toalha, vermiculita e areia, nas temperaturas $20^{\circ} \mathrm{C}$ e $25^{\circ} \mathrm{C}$, e com o substrato rolo de papel na temperatura $30^{\circ} \mathrm{C}$. As sementes germinam tanto na presença como na ausência de luz, bem como em substrato úmido, muito úmido e encharcado, nas temperaturas $20^{\circ} \mathrm{C}$ e $25^{\circ} \mathrm{C}$.
\end{abstract}

Termos para indexação: sementes florestais; murta; comportamento germinativo.

\author{
GERMINATION OF SEEDS OF Blepharocalyx salicifolius (HBK) Berg. IN DIFFERENT \\ SUBSTRATES AND CONDITIONS OF TEMPERATURES, LIGHT AND MOISTURE
}

\begin{abstract}
The objective of this study was to assess the influence of different temperatures $\left(20^{\circ} \mathrm{C}\right.$, $25^{\circ} \mathrm{C}, 30^{\circ} \mathrm{C}$ and $35^{\circ} \mathrm{C}$ ), substrates (roll of paper, paper-towel, sand and vermiculite), conditions of light (absence and presence) and humidity (substrates little humid, humid, very humid and drenched) on the germination of seeds of Blepharocalyx salicifolius. The best results were obtained with the substrate paper towel, vermiculite and sand, in temperatures $20^{\circ} \mathrm{C}$ and $25^{\circ} \mathrm{C}$, and with the substrate roll of paper in the temperature $30^{\circ} \mathrm{C}$. The seeds germinate well in both the presence and the absence of light, as well as substrate humid, very humid and drenched in temperatures $20^{\circ} \mathrm{C}$ and $25^{\circ} \mathrm{C}$.
\end{abstract}

Index terms: seed forest; murta; germination behaviour.

${ }^{1}$ Submetido em 20/10/2008. Aceito para publicação em 13/04/2009. Parte da Dissertação de Mestrado do primeiro autor apresentada a UFPR (Universidade Federal do Paraná).

${ }^{2}$ Bióloga., pós graduanda do Departamento de Ciências Florestais, UFPR, suelen_srego@yahoo.com.br, bolsista CAPES.

${ }^{3}$ Eng. Florestal, Dr., Professor Associado, Dep. de Ciências Florestais,
UFPR, CEP: 80210-170. Curitiba-PR, nogueira@ufpr.br.

${ }^{4}$ Naturalista., Dr., Professora Associada, Dep. de Ciências Florestais, UFPR ,yoshiko@ufpr.br.

${ }^{5}$ Eng. Agr., Dr., Pesquisador, Embrapa Florestas, Caixa postal: 319, CEP. 83411-000. Colombo-PR, alvaro@cnpf.embrapa.br. 


\section{INTRODUÇÃO}

Blepharocalyx salicifolius (H.B.K.) Berg. é uma espécie arbórea da família Myrtaceae, sendo conhecida popularmente como murta.Pode ser encontrada no Paraguai, Uruguai, Argentina (Missiones a Jujuy), Bolívia e Equador. No Brasil, distribui-se nos estados da Bahia, Distrito Federal, Goiás, Minas Gerais, São Paulo, Paraná, Santa Catarina e Rio Grande do Sul, sendo encontrada nas Florestas Estacional Decidual, Estacional Semidecidual, Ombrófila Densa, Ombrófila Mista, em Vegetação com Influência Marinha (Restinga), no Cerrado e Cerradão, e em Estepes ou Campos (Carvalho, 2006). Seu porte varia de pequeno até grande (4 a $30 \mathrm{~m})$, com fuste geralmente reto, podendo chegar a $40 \mathrm{~cm}$ de DAP (Carvalho, 2006; Lorenzi, 1998; Silva Júnior, 2005). É considerada uma espécie secundária tardia ou clímax exigente de luz (Carvalho, 2006), perenifólia, seletiva higrófila, heliófila até esciófila, desenvolvendo-se nos mais variados ambientes ou estágios da vegetação, desde campos abertos até sub-bosques desenvolvidos. É freqüente nas florestas de galeria e em solos úmidos no interior das florestas com araucária (Lorenzi, 1998). Nesses ambientes, é sem dúvida uma das mirtáceas mais expressivas, onde se encontra em estágios mais desenvolvidos (Legrand e Klein, 1978). A madeira é empregada em obras internas de construção civil, para tabuado em geral e, sobretudo para lenha. Devido à sua beleza deveria ser aproveitada para o paisagismo (Lorenzi, 1998). É apropriada para plantios ao longo das margens de rios, por ocorrer naturalmente nesses ambientes e também por ser atrativa à avifauna dispersora de sementes (Carvalho, 2006; Silva Júnior, 2005). O fruto é uma baga globosa de 3 a $5 \mathrm{~mm}$, de coloração alaranjada a avermelhada, glabra, com uma cicatriz quadrangular e possui de uma a 4 sementes. A semente é reniforme, de cor esverdeada, medindo de 4 a $5 \mathrm{~mm}$ de comprimento e o embrião possui a forma de espiral. A maturação dos frutos ocorre de janeiro a março e a dispersão dos frutos e sementes é zoocórica, realizada principalmente pela avifauna e pelo lagarto-teiú (Theju tupinamba) (Carvalho, 2006 e Silva Júnior, 2005 ).

Com a exploração dos recursos naturais, principalmente das espécies arbóreas, visando o uso da madeira e a abertura de novas áreas para a agricultura, as florestas nativas encontram-se fragmentadas e reduzidas a porções muito pequenas em relação às suas áreas originais. Desta forma, visando os programas de recuperação ambiental, a demanda por mudas de espécies florestais nativas tem sido crescente. Visto que, a grande maioria destas é propagada por sementes, o sucesso na formação das mudas depende do conhecimento sobre o processo germinativo de cada espécie e da qualidade da semente utilizada.

O principal atributo da qualidade a ser considerado é a capacidade germinativa das sementes, pois sem ela a semente não tem valor para a semeadura (Figliolia et al., 1993). Cada espécie e variedade têm seus requisitos para a germinação, que são determinados por fatores genéticos e pelas condições em que se formou a semente. Os fatores ambientais que influenciam na germinação estão relacionados com as condições ecológicas e o habitat da planta (Velásquez, 2002).

O fornecimento de água é a condição essencial para que a semente inicie a germinação e se desenvolva (Brasil, 1992). A água influi na germinação, atuando no tegumento, amolecendo-o, favorecendo a penetração do oxigênio, e permitindo a transferência de nutrientes solúveis para as diversas partes da semente (Toledo e Marcos Filho, 1977). A germinação não ocorre em potenciais de água inferiores a determinado ponto crítico, e este varia com a espécie (Popinigis, 1977).

A temperatura é outro fator que tem importante influência sobre o processo germinativo, tanto na porcentagem como na velocidade de germinação. A temperatura influencia na velocidade de absorção de água e nas reações bioquímicas que determinam todo o processo de germinação (Carvalho e Nakagawa, 1983). As sementes possuem comportamento bastante variável frente ao fator temperatura, não havendo uma temperatura ótima e uniforme de germinação para todas as espécies (Borges e Rena, 1993). No entanto, estes autores indicam a faixa de 20 a $30^{\circ} \mathrm{C}$ como adequada para a germinação de um grande número de espécies subtropicais e tropicais, e Piña-Rodrigues et al. (2004) indicam a faixa entre $15^{\circ} \mathrm{C}$ e $30^{\circ} \mathrm{C}$.

O substrato em que a semente é colocada para germinar tem a função de manter a umidade, preservando as condições ideais para que esta ocorra (Piña-Rodrigues e Vieira, 1988). $\mathrm{Na}$ escolha do substrato deve ser levado em consideração o tamanho da semente, sua exigência com relação á quantidade de água, sua sensibilidade ou não à luz e a facilidade que o mesmo oferece para a realização das contagens e para a avaliação das plântulas (Brasil, 1992; Figliolia et al., 1993). Os tipos de substratos mais utilizados, descritos e prescritos nas Regras para Análise de Sementes (Brasil, 1992), são: pano, papel toalha, papel filtro, papel mataborrão, terra e areia. Para as espécies florestais nativas, poucas recomendações e prescrições existem e outros tipos de substratos têm sido testados, tais como carvão, esfagno (Sphagnum) e, principalmente, vermiculita (Figliolia et al., 
1993).

Pela falta de informações sobre a germinação das sementes desta espécie, este trabalho tem por objetivo avaliar o comportamento germinativo das sementes de $B$. salicifolius sob diferentes temperaturas, substratos e condições de luz e umidade.

\section{MATERIAL E MÉTODOS}

Os frutos de B. salicifolius foram coletados de 12 matrizes localizadas no município de Colombo - PR, no mês de março de 2007, com o auxílio de um estilingue para derrubar os galhos, devido à altura elevada das árvores. No momento da coleta, os frutos apresentavam diferentes colorações: verde, amarela, laranja e vermelha, desta forma foi necessário a separação dos frutos com a coloração laranja e vermelha. Amostras de material para herborização foram coletadas, identificadas, registradas e tombadas sob o número 10187, no Herbário Escola de Florestas de Curitiba (EFC) do Departamento de Ciências Florestais da Universidade Federal do Paraná. Os frutos foram armazenados em câmara fria $\left(5^{\circ} \mathrm{C}\right.$ e $80 \%$ de umidade relativa) em embalagens de plástico abertas por um período de dois meses, e os testes de germinação foram realizados durante este período. $\mathrm{O}$ teor de água das sementes logo após a coleta foi de $34 \%$, sendo que este valor se manteve durante o período em que os frutos ficaram armazenados. A extração das sementes foi realizada através da maceração e lavagem dos frutos em água corrente, tomando-se o cuidado para não danificar as sementes, pois estas são frágeis devido ao seu tegumento membranáceo. Posteriormente, as sementes foram deixadas secar em condições ambiente durante 24 horas, sendo que as danificadas foram descartadas.

Análises físicas - foram realizados testes para obter o peso de mil sementes, número de sementes por quilo e o teor de água das sementes, conforme as Regras para Análise de Sementes (Brasil, 1992), e calculado o coeficiente de variação. Para o peso de mil sementes foram utilizadas oito amostras de 100 sementes e a determinação do teor de água das sementes foi obtida através da secagem das sementes em estufa de ventilação forçada a $105^{\circ} \mathrm{C} \pm 3^{\circ} \mathrm{C}$ por 24 horas, utilizando três repetições de 200 sementes.

Substrato e temperatura - foram testados diferentes tipos de substratos: rolo de papel, papel toalha, areia e vermiculita, e temperaturas: $20^{\circ} \mathrm{C}, 25^{\circ} \mathrm{C}, 30^{\circ} \mathrm{C}$ e $35^{\circ} \mathrm{C}$, com seis repetições de 30 sementes por tratamento. Os substratos foram previamente esterilizados em estufa regulada a $105^{\circ} \mathrm{C}$ $\pm 3^{\circ} \mathrm{C}$ durante 24 horas; com exceção do rolo de papel, os substratos foram colocados em caixas de plástico (gerbox) desinfestados com álcool 70\%.

Para o substrato papel toalha foram colocadas três folhas em cada gerbox e umedecidas com água destilada. A areia utilizada foi a de granulometria média entre 0,35 e $1 \mathrm{~mm}$, obtidas com duas peneiras de solos, sendo colocadas $300 \mathrm{~g}$ de areia esterilizada e $60 \mathrm{ml}$ de água destilada no gerbox. A vermiculita utilizada foi a de granulometria média (30g) com $75 \mathrm{ml}$ de água nos gerbox. As sementes foram colocadas sobre os substratos areia e vermiculita. Para o rolo de papel foram utilizadas quatro folhas de papel toalha umedecidas com água destilada, e as sementes foram distribuídas sobre duas folhas e recobertas com outras duas folhas, formando os rolos. Para o substrato papel toalha foi necessário o reumedecimento do substrato, pois este perdeu umidade durante o experimento.

As sementes foram colocadas em germinadores tipo Biomatic regulados às temperaturas de $20^{\circ} \mathrm{C}, 25^{\circ} \mathrm{C}, 30^{\circ} \mathrm{C}$ e $35^{\circ} \mathrm{C}$.

Luz - após a determinação do melhor substrato e temperatura foi testado o efeito luz (ausência e presença de luz), utilizando gerbox pintados com tinta acrílica preta e gerbox transparentes. Foram colocadas seis repetições de 30 sementes por tratamento, em gerbox, contendo $30 \mathrm{~g}$ de vermiculita média e $75 \mathrm{ml}$ de água destilada, na temperatura de $25^{\circ} \mathrm{C}$. As avaliações foram realizadas em ambiente escuro sob uma lâmpada incandescente de $60 \mathrm{~W}$ e recoberta com filtro verde.

Quantidade de água no substrato e temperatura - em outro experimento testaram-se também diferentes quantidades de água no substrato e diferentes temperaturas. Foram colocados $30 \mathrm{~g}$ de vermiculita média em gerbox e adicionados 1,$5 ; 2,5 ; 3,5$ e 4,5 vezes o peso do substrato em quantidade de água $(45,75,105$ e $135 \mathrm{ml}$ de água), que corresponderam aos substratos pouco úmido, úmido, muito úmido e encharcado. Foram utilizadas seis repetições de 30 sementes por tratamento e colocadas em germinador regulado às temperaturas de $20^{\circ} \mathrm{C}, 25^{\circ} \mathrm{C}$ e $30^{\circ} \mathrm{C}$.

A avaliação da germinação, em todos os experimentos, foi diária, sendo iniciada já no primeiro dia após a instalação do teste e encerrada no $51^{\circ}$ dia quando as sementes já não germinaram mais. As sementes foram consideradas germinadas, quando apresentaram emissão de radícula, com no mínimo $2 \mathrm{~mm}$. Foram avaliados a porcentagem, o tempo médio (TM) e o índice de velocidade de germinação (IVG) e calculados de acordo com as fórmulas propostas por Laboriau (1983) e Maguire (1962).

Os testes de germinação foram conduzidos no delineamento inteiramente casualizado. A influência da 
temperatura e do substrato foi analisada em esquema fatorial 4 x 4 (4 temperaturas $x 4$ substratos) e a influência de diferentes quantidades de água e temperaturas em esquema fatorial $4 \times 3$ (4 quantidades de água x 3 temperaturas). Os dados obtidos para a porcentagem, TM e IVG foram submetidos ao teste de Bartlett. Quando as variâncias foram homogêneas, os dados foram submetidos à análise de variância, e as médias comparadas entre si pelo teste de Tukey a $5 \%$ de probabilidade. Em variâncias não homogêneas utilizou-se a estatística não-paramétrica por meio do teste de KruskalWallis e as médias comparadas por comparações múltiplas não paramétricas a 5\% de probabilidade (Siegel e Castellan, 1988). Nos testes de germinação para o efeito luz (ausência e presença) foi realizado o teste $\mathrm{F}$ para verificar homogeneidade das variâncias e as médias comparadas pelo teste T a 5\% de probabilidade.

\section{RESULTADOS E DISCUSSÃO}

Análises físicas - obteve-se 20,87g $(\mathrm{CV}=4,55 \%)$ para o peso de mil sementes, 47.904 sementes por quilo e o teor de água de $34,57 \%(\mathrm{CV}=1,27 \%)$ diferentemente do encontrado por Lorenzi (1998) de 65.000 sementes/kg e Nogueira et al. (2002): 15,53g para o peso de mil sementes, 64.257 sementes/ $\mathrm{kg}$ e o teor de água de $20,49 \%$. Estes resultados distintos se devem ao teor de água baixo encontrado por Nogueira et al. (2002), o que proporcionou menor peso, e com isso maior número de sementes por quilo. Provavelmente os dados do número de sementes por quilos encontrados por Lorenzi (1998) advêm de sementes com menor teor de água.

Substrato e temperatura - Pela análise de variância pode-se observar que houve interação entre as temperaturas e os substratos para os três índices avaliados: porcentagem, TM e IVG. Os substratos papel toalha, rolo de papel, vermiculita e areia nas temperaturas $20^{\circ} \mathrm{C}$ e $25^{\circ} \mathrm{C}$, e o substrato rolo de papel na temperatura $30^{\circ} \mathrm{C}$ proporcionaram os maiores valores de porcentagem de germinação. Na temperatura de $35^{\circ} \mathrm{C}$ observaram-se os menores valores de porcentagem de germinação em todos os substratos testados, chegando a $36,7 \%$ no substrato vermiculita, e os menores valores para o IVG nos substratos vermiculita e areia (Tabela 1). Das sementes que não germinaram, na temperatura $35^{\circ} \mathrm{C}, 50 \%$ estavam deterioradas quando utilizados os substratos papel toalha, rolo de papel e areia, e $60 \%$ com o substrato vermiculita, provavelmente devido à presença dos fungos Penicillium sp. e Pestalotia sp. . Desta forma, verifica-se que como as sementes não germinaram nesta temperatura, o processo de deterioração foi acelerado ocorrendo lixiviação do conteúdo celular e criando ambiente propício para o desenvolvimento destes fungos. A temperatura $30^{\circ} \mathrm{C}$ também prejudicou a germinação das sementes, apresentando os menores valores de porcentagem de germinação, exceto para o substrato rolo de papel que não diferiu estatisticamente das temperaturas $20^{\circ} \mathrm{C}$ e $25^{\circ} \mathrm{C}$ (Tabela 1 ).

Nas temperaturas $20^{\circ} \mathrm{C}$ e $25^{\circ} \mathrm{C}$, os substratos papel toalha, vermiculita e areia proporcionaram os maiores valores para o IVG e o menor TM, sendo que o substrato rolo de papel, nestas temperaturas, apresentou os menores valores (Tabela $1)$.

Desta forma, verifica-se que para a obtenção dos melhores resultados para a germinação de sementes de $B$. salicifolius deve-se utilizar os substratos papel toalha, vermiculita ou areia, nas temperaturas $20^{\circ} \mathrm{C}$ e $25^{\circ} \mathrm{C}$, e o substrato rolo de papel, na temperatura $30^{\circ} \mathrm{C}$. Resultados semelhantes foram encontrados por Nogueira et al. (2002) que testaram os substratos areia, vermiculita e papel filtro, e as temperaturas de $25^{\circ} \mathrm{C}$ e $30^{\circ} \mathrm{C}$ na germinação das sementes desta espécie, e verificaram que o melhor tratamento foi com a temperatura de $25^{\circ} \mathrm{C}$ e o substrato vermiculita. No entanto, estes autores obtiveram apenas $40 \%$ de germinação para $B$. salicifolius, e de acordo com Lorenzi (1998) a germinação das sementes desta espécie geralmente é menor que $50 \%$. O que não foi verificado neste trabalho, pois nas condições adequadas de temperatura e umidade, a germinação foi superior a $90 \%$.

As temperaturas ideais para a germinação de $B$. salicifolius encontradas neste trabalho estão na faixa de $20^{\circ} \mathrm{C}$ a $30^{\circ} \mathrm{C}$, que de acordo com Borges e Rena (1993) mostrase adequada para a germinação de um grande número de espécies subtropicais e tropicais.

As temperaturas próximas à superfície do solo podem variar bastante entre os ambientes. Grandes clareiras nas florestas tropicais, por exemplo, podem apresentar maiores amplitudes térmicas do que em locais sombreados do subbosque (Melo et al., 2004). Como B. salicifolius é considerada uma espécie secundária tardia ou clímax, é esperado que suas sementes apresentem baixa porcentagem de germinação em temperaturas elevadas $\left(35^{\circ} \mathrm{C}\right)$.

Apesar de o substrato papel toalha estar entre os melhores para a germinação das sementes B. salicifolius, estas possuem germinação lenta e com isto este substrato precisou ser reumedecido com mais freqüência, além de apresentar baixa resistência quando disposto em rolos de papel. A vermiculita tem sido o substrato mais empregado em espécies florestais pelos excelentes resultados demonstrados, e por ser mais leve que a areia, seu manejo é facilitado (Piña- 
Rodrigues e Vieira, 1988; Piña-Rodrigues et al., 2004). Como as sementes de $B$. salicifolius são de tamanho médio, não apresentam problemas em ser confundidas com este substrato, que proporcionou juntamente com os demais elevadas porcentagens de germinação para esta espécie. Pacheco et al. (2006), Maluf e Pisciottano Ereio (2005) e Pereira (1992) também verificaram que no substrato vermiculita houve um bom desempenho germinativo e não exigiu reumedecimento diário, mostrando-se adequado para a avaliação da qualidade fisiológica de sementes de Myracrodruon urundeuva, Campomanesia phaea e Bauhinia forficata.

TABELA 1. Porcentagem, tempo médio e índice de velocidade de germinação das sementes de Blepharocalyx salicifolius em diferentes substratos e temperaturas.

\begin{tabular}{|c|c|c|c|c|}
\hline \multirow[t]{3}{*}{ Substratos } & \multicolumn{4}{|c|}{ Temperaturas } \\
\hline & \multicolumn{4}{|c|}{ \% Germinação } \\
\hline & $20^{\circ} \mathrm{C}$ & $25^{\circ} \mathrm{C}$ & $30^{\circ} \mathrm{C}$ & $35^{\circ} \mathrm{C}$ \\
\hline Papel toalha & $97,8 \mathrm{Aa}$ & 93,9 Aa & $78,9 \mathrm{Ab}$ & $55,0 \mathrm{Bc}$ \\
\hline Rolo de papel & $96,1 \mathrm{Aa}$ & 93,9 Aa & $86,1 \mathrm{Aa}$ & $68,9 \mathrm{Ab}$ \\
\hline Areia & $96,7 \mathrm{Aa}$ & $94,5 \mathrm{Aa}$ & $77,2 \mathrm{Ab}$ & $47,2 \mathrm{Bc}$ \\
\hline \multirow[t]{3}{*}{ Vermiculita } & $96,1 \mathrm{Aa}$ & $92,8 \mathrm{Aa}$ & $77,2 \mathrm{Ab}$ & $36,7 \mathrm{Cc}$ \\
\hline & \multicolumn{4}{|c|}{$\mathrm{TM}$} \\
\hline & $20^{\circ} \mathrm{C}$ & $25^{\circ} \mathrm{C}$ & $30^{\circ} \mathrm{C}$ & $35^{\circ} \mathrm{C}$ \\
\hline Papel toalha & $21,0 \mathrm{ABa}$ & $20,7 \mathrm{ABa}$ & 17,8 Aab & $13,0 \mathrm{Ab}$ \\
\hline Rolo de papel & $23,8 \mathrm{Aa}$ & $21,6 \mathrm{Aa}$ & $19,4 \mathrm{Aa}$ & $14,3 \mathrm{Ab}$ \\
\hline Areia & $19,4 \mathrm{Ba}$ & $18,1 \mathrm{Ba}$ & $16,1 \mathrm{Aa}$ & $14,7 \mathrm{Aa}$ \\
\hline \multirow[t]{3}{*}{ Vermiculita } & $20,2 \mathrm{Ba}$ & $17,5 \mathrm{Bb}$ & 18,3 Aab & $16,5 \mathrm{Ab}$ \\
\hline & \multicolumn{4}{|c|}{ IVG } \\
\hline & $20^{\circ} \mathrm{C}$ & $25^{\circ} \mathrm{C}$ & $30^{\circ} \mathrm{C}$ & $35^{\circ} \mathrm{C}$ \\
\hline Papel toalha & $1,5 \mathrm{ABa}$ & 1,6 Aba & $1,6 \mathrm{Aa}$ & $1,5 \mathrm{Aa}$ \\
\hline Rolo de papel & $1,4 \mathrm{Bb}$ & 1,5 Bb & $1,6 \mathrm{Ab}$ & $1,7 \mathrm{Aa}$ \\
\hline Areia & $1,7 \mathrm{Aa}$ & 1,8 Aa & $1,8 \mathrm{Aa}$ & $1,3 \mathrm{Ab}$ \\
\hline Vermiculita & $1,6 \mathrm{Aa}$ & $1,8 \mathrm{Aa}$ & $1,7 \mathrm{Aa}$ & $0,9 \mathrm{Bb}$ \\
\hline
\end{tabular}

Médias seguidas por letras distintas maiúsculas nas colunas e minúsculas nas linhas diferem entre si pelo teste de Tukey a 5\% de probabilidade (\% germinação) e pelo teste de comparação múltipla não paramétrica a $5 \%$ de probabilidade (IVG, TM).

Um fator importante a ser considerado é a interação temperatura e substrato, pois a capacidade de retenção de água pelo substrato pode ser responsável por diferentes respostas obtidas até para a mesma temperatura (Figliolia et al., 1993). Neste trabalho observou-se que o substrato rolo de papel proporcionou maior porcentagem de germinação, em relação aos demais substratos, nas temperaturas $30^{\circ} \mathrm{C}$ e $35^{\circ} \mathrm{C}$. Este fato também pode ser atribuído a uma maior área de contato entre as sementes e o substrato rolo de papel, o que não ocorreu nos substratos vermiculita, areia e o papel toalha em gerbox, pois as sementes ficaram só com uma parte em contato com estes substratos.

Analisando a Figura 1 pode-se verificar que a germinação na temperatura $20^{\circ} \mathrm{C}$ e $25^{\circ} \mathrm{C}$, nos substratos papel toalha, rolo de papel, areia e vermiculita e na temperatura $30^{\circ} \mathrm{C}$ com o substrato rolo de papel inicia-se entre o $6^{\circ}$ e o $8^{\circ}$ dia após a semeadura, e a partir do $36^{\circ}$ dia ocorre a estabilização das curvas de germinação. Esse resultado sugere que a avaliação da protrusão radicular de sementes de $B$. salicifolius, nas temperaturas e nos substratos citados, pode ser iniciada a partir do $6^{\circ}$ dia após a instalação do teste e ser encerrada no $36^{\circ}$ dia. 

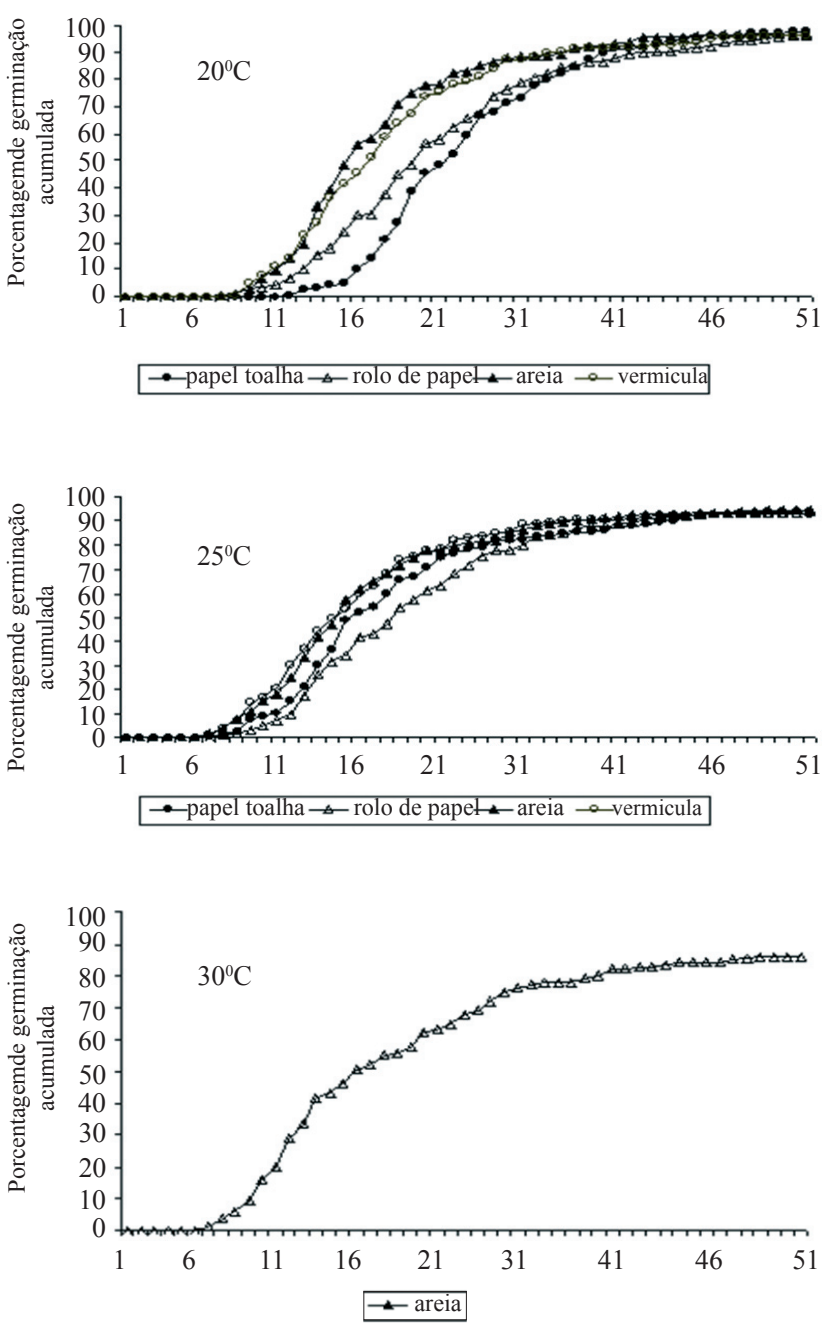

FIGURA 1. Porcentagem de germinação acumulada de sementes de Blepharocalyx salicifolius na temperatura de $20^{\circ} \mathrm{C}, 25^{\circ} \mathrm{C}$ e $30^{\circ} \mathrm{C}$ em diferentes substratos.

Luz - os resultados do teste-T revelaram que não houve diferença significativa entre as médias da porcentagem de germinação das sementes de $B$. salicifolius para os tratamentos com e sem luz. Para o TM e para o IVG as médias do tratamento sem luz foram estatisticamente diferentes do tratamento com luz, apresentando o maior IVG e o menor TM (Tabela 2). Uma germinação em menor tempo pode conferir vantagens, pois quanto mais rápida for a germinação das sementes, estas permanecerão por menos tempo sob condições adveras como redução da umidade do solo e ação de microrganismos (Martins et al., 1999), aumentando as possibilidades para o estabelecimento das plântulas.
TABELA 2. Porcentagem, tempo médio e índice de velocidade de germinação das sementes de Blepharocalyx salicifolius com e sem luz.

\begin{tabular}{lccc}
\hline & \% Germinação & TM & IVG \\
\hline Com luz & $97,22 \mathrm{~A}$ & $12,73 \mathrm{~A}$ & $2,55 \mathrm{~B}$ \\
Sem luz & $97,78 \mathrm{~A}$ & $11,27 \mathrm{~B}$ & $2,88 \mathrm{~A}$ \\
\hline
\end{tabular}

Médias seguidas por letras distintas diferem entre si pelo teste-T a 5\% de probabilidade

De acordo com Figliolia e Piña-Rodrigues (1995) e Melo et al. (2004) as exigências das sementes quanto à luz estão relacionadas com os diferentes grupos ecológicos: pioneiras, secundárias e clímax. Geralmente as espécies clímax conseguem germinar e se estabelecer sob condições de pouca disponibilidade de luz, e são capazes de germinar sob o dossel da floresta, e as secundárias germinam em condições de luz e de sombra. B. salicifolius é considerada uma espécie secundária tardia ou clímax, desenvolvendo-se nos mais variados ambientes ou estágios da vegetação, desde campos abertos até sub-bosques desenvolvidos (Carvalho, 2006; Lorenzi, 1998). Sendo assim, esta classificação está de acordo com os resultados obtidos neste trabalho, pois as sementes germinam tanto na presença como na ausência de luz. Resultados semelhantes foram verificados por Silva et al. (2001) em sementes de Schinus terebinthifolius, espécie secundária típica, que apresentou um bom comportamento germinativo tanto na ausência como na presença de luz, embora temperaturas elevadas inibissem a germinação.

Apesar da validade e da utilidade do conceito de pioneiras e tolerantes à sombra (secundárias e clímax), é preciso ressaltar que estudos têm identificado espécies nas florestas tropicais com requerimentos intermediários de luz e que compartilham características biológicas comuns a ambos os grupos (Melo et al., 2004). Como por exemplo, em Mabea fistulifera, que cresce naturalmente em capoeiras e em clareiras na floresta, mas o comportamento de suas sementes apresenta características diferentes das esperadas em tais circunstâncias, como indiferença ao fator luz, germinando tanto na luz como no escuro, e temperaturas altas $\left(35^{\circ} \mathrm{C}\right)$ diminuíram a porcentagem de germinação (Leal Filho e Borges, 1992).

Quantidade de água no substrato e temperatura para a porcentagem de germinação, houve interação entre as temperaturas e as diferentes quantidades de água no substrato. Quanto ao IVG e ao TM não houve interação entre 
os fatores.

Na porcentagem de germinação não houve diferença estatística entre as diferentes quantidades de água no substrato nas três temperaturas estudadas: $20^{\circ} \mathrm{C}, 25^{\circ} \mathrm{C}$ e $30^{\circ} \mathrm{C}$, no entanto, para o IVG os substratos muito úmido e encharcado apresentaram os valores correspondentes as maiores velocidades de germinação, e o substrato úmido, juntamente com o muito úmido e o encharcado apresentaram os menores valores para o TM (Tabela 3). Desta forma, verifica-se que as sementes de $B$. salicifolius germinam melhor nos substratos úmido, muito úmido e encharcado, nas temperaturas $20^{\circ} \mathrm{C}$ e $25^{\circ} \mathrm{C}$, pois no substrato pouco úmido os valores do TM e IVG foram inferiores aos obtidos para os substratos muito úmidos e encharcados, e na temperatura $30^{\circ} \mathrm{C}$ a porcentagem de germinação foi inferior às demais temperaturas em todas as quantidades de água estudadas.

TABELA 3. Porcentagem, tempo médio e índice de velocidade de germinação das sementes de Blepharocalyx salicifolius em diferentes quantidades de água no substrato e temperaturas.

\begin{tabular}{|c|c|c|c|c|}
\hline \multirow[t]{3}{*}{ Quantidade de Água } & \multicolumn{4}{|c|}{ Temperaturas } \\
\hline & \multicolumn{4}{|c|}{ \% Germinação } \\
\hline & $20^{\circ} \mathrm{C}$ & $25^{\circ} \mathrm{C}$ & $30^{\circ} \mathrm{C}$ & Médias \\
\hline Pouco úmido & $93,3 \mathrm{Aa}$ & $95,6 \mathrm{Aa}$ & $78,3 \mathrm{Ab}$ & - \\
\hline Úmido & $96,7 \mathrm{Aa}$ & $94,4 \mathrm{Aa}$ & $80,6 \mathrm{Ab}$ & - \\
\hline Muito úmido & $97,8 \mathrm{Aa}$ & $98,3 \mathrm{Aa}$ & $83,9 \mathrm{Ab}$ & - \\
\hline \multirow[t]{3}{*}{ Encharcado } & $99,4 \mathrm{Aa}$ & $97,2 \mathrm{Aab}$ & $87,2 \mathrm{Ab}$ & - \\
\hline & \multicolumn{4}{|c|}{ TM } \\
\hline & $20^{\circ} \mathrm{C}$ & $25^{\circ} \mathrm{C}$ & $30^{\circ} \mathrm{C}$ & Médias \\
\hline Pouco úmido & 18,4 & 14,0 & 12,3 & $14,9 \mathrm{~A}$ \\
\hline Úmido & 16,7 & 12,8 & 11,8 & $13,7 \mathrm{AB}$ \\
\hline Muito úmido & 14,3 & 12,0 & 9,7 & $12,0 \mathrm{~B}$ \\
\hline Encharcado & 14,1 & 10,6 & 9,1 & $11,26 \mathrm{~B}$ \\
\hline \multirow[t]{3}{*}{ Médias } & $15,9 \mathrm{~A}$ & $12,3 \mathrm{~B}$ & $10,7 \mathrm{~B}$ & \\
\hline & \multicolumn{4}{|c|}{ IVG } \\
\hline & $20^{\circ} \mathrm{C}$ & $25^{\circ} \mathrm{C}$ & $30^{\circ} \mathrm{C}$ & Médias \\
\hline Pouco úmido & 1,7 & 2,3 & 2,2 & $2,0 \mathrm{~B}$ \\
\hline Úmido & 1,9 & 2,5 & 2,4 & $2,2 \mathrm{BC}$ \\
\hline Muito úmido & 2,2 & 2,8 & 3,0 & $2,6 \mathrm{AC}$ \\
\hline Encharcado & 2,3 & 3,0 & 3,2 & $2,8 \mathrm{~A}$ \\
\hline Médias & $2,0 \mathrm{~B}$ & $2,65 \mathrm{~A}$ & $2,7 \mathrm{~A}$ & \\
\hline
\end{tabular}

O teor de água e o substrato exigido pelas sementes estão relacionados com as características ecológicas de cada espécie. Espécies com sementes de tamanho médio a grande e que ocorrem nas encostas úmidas e nas margens de rios os substratos mais granulados e úmidos são mais indicados (Piña-Rodrigues et al., 2004). Como B. salicifolius é particularmente frequente em solos úmidos (Lorenzi,
1998) explica o fato das sementes germinarem melhor em substratos úmidos, muito úmidos e encharcados, do que em substratos pouco úmidos.

Os resultados encontrados para B. salicifolius foram similares aos encontrados por Figliolia e Silva (1998) para Genipa americana, também característica de floresta pluvial, para a qual o melhor comportamento germinativo 
foi obtido nos substratos úmido, muito úmido e encharcado, e Silva et al. (2001) para Schinus terebinthifolius, espécie que ocorre nas margens de rios, obteve melhores resultados de germinação nos substratos úmido e muito úmido. Schizolobium amazonicum também apresentou este comportamento, obtendo o melhor desempenho germinativo nas quantidades de água de 2,5 e 3,0 vezes a massa do papel, que corresponderiam ao substrato úmido e ao muito úmido, demonstrando que esta espécie necessita de maior quantidade de água para acelerar o processo germinativo (Ramos et al., 2006). Já as sementes de Gallesia integrifolia germinaram melhor em substratos menos úmidos, principalmente com 45 e $90 \mathrm{ml}$ de água em $30 \mathrm{~g}$ de vermiculita média (Barros et al., 2005).

\section{CONCLUSÕES}

Os melhores resultados para a germinação de sementes de $B$. salicifolius são obtidos com os substratos papel toalha, vermiculita e areia, nas temperaturas $20^{\circ} \mathrm{C}$ e $25^{\circ} \mathrm{C}$, e com o substrato rolo de papel na temperatura $30^{\circ} \mathrm{C}$.

As sementes de B. salicifolius germinam tanto na presença como na ausência de luz.

Os substratos úmido, muito úmido e o encharcados, nas temperaturas $20^{\circ} \mathrm{C}$ e $25^{\circ} \mathrm{C}$ favorecem a germinação.

\section{REFERÊNCIAS}

BARROS, S.S.U.; SILVA, A. da; AGUIAR, I.B. Germinação de sementes de Gallesia integrifolia (Spreng.) Harms (paud'alho) sob diferentes condições de temperatura, luz e umidade do substrato. Revista Brasileira de Botânica, v.28, n.4, p.727-733, 2005.

BORGES, E.E. de L. e; RENA, A.B. Germinação de sementes In: AGUIAR, I.B. de; PIÑA-RODRIGUES, F.C.M.; FIGLIOLIA, M.B. Sementes florestais tropicais. Brasília, DF: ABRATES, 1993. p. 83-135.

BRASIL, Ministério da Agricultura e da Reforma Agrária. Regras para análises de sementes. Brasília, DF: SNDA/ DNDV/CLAV, 1992. 365p.

CARVALHO, P.E.R. Espécies arbóreas brasileiras. Colombo: Embrapa Florestas, 2006. v. 2, 627p.

CARVALHO, N.M. de; NAKAGAWA, J. Sementes: ciência, tecnologia e produção. Campinas: Fundação Cargill, 1983. 429p.

FIGLIOLIA, M.B.; OLIVEIRA, E. de C.; PINÃRODRIGUES, F.C.M. Análise de sementes In: AGUIAR,
I.B. de; PIÑA-RODRIGUES, F.C.M.; FIGLIOLIA, M.B. Sementes florestais tropicais. Brasília, DF: ABRATES, 1993. p. 137-174.

FIGLIOLIA, M.B.; PIÑA-RODRIGUES, F.C.M. Considerações práticas sobre o teste de germinação: manual técnico de sementes florestais. IF Série Registros, São Paulo, n.14, p. 45-59, 1995.

FIGLIOLIA, M.B.; SILVA, M.C.C. Germinação de sementes de jenipapeiro (Genipa americana L. - Rubiaceae) sob diferentes regimes de temperatura, umidade e luz. Revista do Instituto Florestal, v. 10, n. 1, p. 63-72, 1998.

LABORIAU, L.G. A germinação das sementes. Washington: Secretaria Geral da Organização dos Estados Americanos, 1983. 174p.

LEAL FILHO, N.; BORGES, E.E. de L. e. Influência da temperatura e da luz na germinação de sementes de canudo de pito (Mabea fistulifera Mart.). Revista Brasileira de Sementes, v. 14, n. 1, p. 57-60, 1992.

LEGRAND, D.C.; KLEIN, R. Mirtáceas. v. 17-22. In: REITZ, P.R. Flora ilustrada catarinense. Itajaí: Herbário Barbosa Rodrigues, 1978. 876p.

LORENZI, H. Árvores brasileiras: manual de identificação e cultivo de plantas arbóreas nativas do Brasil. 2 ed. Nova Odessa: Plantarum, 1998. 352p.

MAGUIRE, J.D. Speed of germination aid in selection and evaluation for seedling emergence and vigor. Crop Science, v.2, n.1, p. 176-177. 1962.

MALUF, A.M.; PISCIOTTANO-EREIO, W.A. Secagem e armazenamento de sementes de cambuci. Pesquisa Agropecuária Brasileira, v. 40, n. 7, p. 707-714, 2005.

MARTINS, C.C.; NAKAGAWA, J.; BOVI, M.L. Efeito da posição da semente no substrato e no crescimento inicial das plântulas de palmito vermelho (Euterpe espiritosantensis Fernades - Palmae). Revista Brasileira de Sementes, v. 1, n. 1, p. 164-173, 1999.

MELO,F.P.L.de;AGUIARNETO,A.V.de;SIMABUKURO, E.A.; TABARELLI, M. Recrutamento e estabelecimento de plântulas. In: FERREIRA, A.G.; BORGHETTI, F. Germinação - do básico ao aplicado. Porto Alegre: Artmed, 2004. p. 237-250.

NOGUEIRA, A.C.; PORTELA, O.; NAZÁRIO, P. Comportamento germinativo das sementes de Blepharocalyx salicifolius (Kunth) O. Berg. In: CONGRESSO NACIONAL DE BOTÂNICA, 53., 2002, Recife. Anais... Recife: Sociedade Botânica do Brasil, 2002. p. 29.

PACHECO, M. V.; MATOS, V. P.; FERREIRA, R. L. 
C.; FELICIANO, A. L. P.; PINTO, K. M. S. Efeito de temperaturas e substratos na germinação de sementes de Myracrodruon urundeuva Fr. All. (Anacardiaceae). Revista Árvore, v.30, n.3, p.359-367, 2006.

PEREIRA, T.S. Germinação de sementes de Bauhinia forficata Link. (Leguminosae Caesalpinoideae). Revista Brasileira de Sementes, v. 14, n. 1, p. 77-82, 1992.

PIÑA-RODRIGUES,F.C.M.;FIGLIOLIA,M.B.;PEIXOTO, M.C. Tecnologia de sementes: Testes de qualidade. In: FERREIRA, A.G.; BORGHETTI, F. Germinação - do básico ao aplicado. Porto Alegre: Artmed, 2004. p. 265282.

PIÑA-RODRIGUES, F.C.M.; VIEIRA, J.D. Teste de germinação. In: PIÑA-RODRIGUES, F.C.M. Manual de análise de sementes florestais. Campinas: Fundação Cargill, 1988. p. 70-90.

POPINIGIS, F. Fisiologia da semente. Brasília: AGIPLAN, 1977. 289p.

RAMOS, M. B. P.; VARELA, V. P.; MELO M. de F. Influência da temperatura e da água sobre a germinação de sementes de paricá (Schizolobium amazonicum Huber Ex Ducke-Leguminosae-Caesalpinioideae). Revista Brasileira de Sementes, v. 28, n. 1, p.163-168, 2006.

SIEGEL, S; CASTELLAN, J. Non parametric statistics for the behavioral sciences. New York: MacGraw Hill Int., 1988. 350p.

SILVA, M.C.C. da; NAKAGAWA, J.; FIGLIOLIA, M.B. Influência da temperatura, da luz e do teor de água na germinação de sementes de Schinus terebinthifolius Raddi - Anacardiaceae (aroeira-vermelha). Revista do Instituto Florestal, v. 13, n. 2, p. 135-146, 2001.

SILVA JÚNIOR, M. C. da. 100 árvores do Cerrado: guia de campo. Brasília, DF: Rede de Sementes do Cerrado. 2005. 278 p.

TOLEDO, F.F. de; MARCOS FILHO, J.M. Manual das sementes: tecnologia e produção. São Paulo: Agronômica Ceres, 1977. 224p.

VELÁSQUEZ, J.C. Fisiologia de semillas y plántulas. Medellín: Universidad Nacional de Colômbia, 2002. 153p. 